\title{
Bibliografia prac naukowych prof. dr habil. Ludwika Lysiaka*
}

Die Bibliographie der wissenschaftlichen Arbeiten

von Prof. Dr. habil. Ludwik Lysiak

1953

1. Karta $z$ dziejów solectw dawnej Rzeczypospolitej, Czasopismo Prawno-Historyczne, t. V, s. 265-270.

1954

2. Registratura Sqdu Krajowego Karnego $w$ Krakowie $i$ jej brakowanie, Archeion, t. XXII, s. 156-195; sum., s. 254-255.

3. Rec. [L. Ż Yтkоwicz, Revisio Bonorum Episcopatus Vladislaviensis Facta a. 1598 (Inwentarz dóbr stolowych biskupa wloclawskiego z r. 1598), Towarzystwo Naukowe w Toruniu, Fontes, t. 36, Torun 1950, s. IX + 252]; Kwartalnik Historyczny, LXI, nr 3, s. 239-247.

\section{5}

4. Sad szlachecki $w$ Tarnowie 1787-1855. Studium archiwalne $z$ dziejów kancelarii i registratur sqdowych $w$ Galicji, Archeion, t. XXIV, s. 305-328; sum., s. 395 i 400.

5. Rec.: [L. Ż Y TK OW I cz, Revisio bonorum episcopatus Vladislaviensis facta a. 1582 (Inwentarz dóbr stolowych biskupstwa wloclawskiego z roku 1582), Towarzystwo Naukowe w Toruniu, Fontes, t. 37, Toruń 1953, s. XXIV + 394], Archeion, t. XXIV, s. 378-384.

6. $O$ zasadach indeksowania źródel prawnych. Sprawozdanie z dzialalności Komisji Redakcyjnej Wydawnictw Źródlowych Komitetu Nauk Prawnych $P A N$, Czasopismo Prawno-Historyczne, t. VII, z. 1, s. 398-401.

* Oznaczenia gwiazdkowe zastosowano w wypadkach podwójnego datowania publikacji. (Publikacje te zamieszczono pod rokiem wydania). 
1956

7. Akta sadowe $X I X i X X$ wieku, Archeion, t. XXV, s. 64-84; sum., s. 419 i 423 .

1957

8. Rec.: W sprawie wydawnictw akt sejmikowych. Uwagi na tle analizy tomu II Akt sejmikowych województwa krakowskiego [A. P R ZYвоŚ, Akta sejmikowe województwa krakowskiego, t. II, 1621-1650. Wrocław, Kraków 1953-1955], Czasopismo Prawno-Historyczne, t. IX, z. 1, s. 255-281.

- Rec. (Sprawozdanie): W. Dworzaczex, Kwartalnik Historyczny 1958, LXIV, nr 2, s. 599 .

\section{8}

9. Współaut:: A. Ptaśnik owa, H. Z a jacowa, Archiwum Naczelnego Komitetu Narodowego (1914-1920), Studia Źródłoznawcze, t. III, s. $139-152$.

10. Współaut.: S. R OMAN, Polskie statuty ziemskie $w$ redakcji najstarszych druków (Syntagmata), Starodawne Prawa Polskiego Pomniki, red. A. Vetulani, Seria 2: Pomniki Prawa Polskiego, Dział I: Prawo Ziemskie, t. II, Wyd. PAN, Zakład Narodowy im. Ossolińskich, Instytut Nauk Prawnych, Wrocław, Kraków, ss. 235.

- Rec.: J. M ATUSZE wski, Czasopismo Prawno-Historyczne 1959, t. XI, z. 1, s. 211-218.

11. Wspólaut.: A. Ptaśnikowa, H. Zajacowa, Inwentarz Archiwum Naczelnego Komitetu Narodowego (1914-1920), wyd. 1, red. H. Altman, Naczelna Dyrekcja Archiwów Państwowych, Archiwum Miasta Krakowa i Województwa Krakowskiego, Warszawa, ss. 140, 2 nlb., tab.

- Rec.: T. M ENCEL, Archeion 1961, t. XXXIV, s. 201-205.

\section{9}

12. Współaut.: A. WANDAS, Indeks rzeczowy wyrazów i form, [w:] Ruski przeklad polskich statutów ziemskich z rekopisu moskiewskiego, Starodawne Prawa Polskiego Pomniki, red. S. Roman, A. Vetulani, Seria 2: Pomniki Prawa Polskiego, Dzial I: Prawo Ziemskie, t. I, Naczelna Dyrekcja Archiwów Państwowych, Archiwum Państwowe Miasta Krakowa i Województwa Krakowskiego, Wyd. PAN, Zakład Narodowy im. Ossolińskich, Instytut Nauk Prawnych, Wroclaw, Kraków, s. 234-244.

13. Głos w dyskusji nad ksiegami sądowymi wiejskimi: VIII Powszechny Zjazd Historyków Polskich w Krakowie 14-17 września 1958 (referaty $i$ dyskusje), Historia Państwa i Prawa, sekcja VII, red. Z. Kaczmarczyk, Polskie Towarzystwo Historyczne, Warszawa, s. 122-124.

14. Obrona pracy doktorskiej mgra Stanislawa Grodziskiego (pt. Ludzie luźni. Studium $z$ historii państwa $i$ prawa polskiego), Czasopismo Prawno-Historyczne, t. XI, z. 2, s. 340. 


\section{0}

15. Ksiegi sqdowe wiejskie $i$ ich znaczenie dla badan nad prawem chlopskim $w$ Polsce feudalnej, Zeszyty Naukowe Uniwersytetu Jagiellońskiego, nr 192, Prace Prawnicze, z. 37, s. 113-117.

\section{2}

16. W sprawie genezy ksiag sqdowych wiejskich, Czasopismo Prawno-Historyczne, t. XIV, z. 2, s. 175-194.

- Rec.: S. G R ODZIsKI, Jeszcze o ksiegach sqdowych, Czasopismo Prawno-Historyczne 1963, t. XV, z. 1, s. $287-292$.

\section{3}

17. W sprawie genezy ksiag sqdowych wiejskich (po raz drugi), Czasopismo Prawno-Historyczne, t. XV, z. 1, s. 293-297.

18. Wspólaut.: S. $\mathrm{P}_{£ \mathrm{AZA}}$, Indeksy [w:] Ksiegi sqdowe wiejskie klucza lackiego, t. 2: (1744-1811), Starodawne Prawa Polskiego Pomniki, red. A. Vetulani, Seria 2: Pomniki Prawa Polskiego, Dział II: Prawo Wiejskie, t. 3, Wrocław, Warszawa, Kraków, s. 223-284.

\section{4}

19. Wlasność soltysia (wójtowska) w Malopolsce do końca XVI w., Zeszyty Naukowe Uniwersytetu Jagiellońskiego, nr 94, Prace Prawnicze, z. 15, ss. 191.

I Rec:: T. LALIK, Przegląd Historyczny 1965, t. LVI, z. 3, s. 508-512.

- Rec.: J. W yrozumski, Małopolskie Studia Historyczne 1966, t. IX, z. 1-2 (32/33), S. $135-138$.

- Rec.: F. Soukup, Právněhistorické Studie, Ceskoslovenská Akademie Véd., t. XIII, Praha 1967, s. 296.

20. U podstaw formowania sie polskiego stanu soltysiego, Czasopismo Prawno-Historyczne, t. XVI, z. 1, s. 231-251.

21. Malopolskie dokumenty lokacyjne w praktyce sqdowej XIV-XVI wieku, Czasopismo Prawno-Historyczne t. XVI, z. 2, s. 45-67.

a Rec.: A. Gasiorowski, Roczniki Historyczne 1966, XXXII, s. 257-260.

\section{5}

22. Ksiega sqdowa kresu klimkowskiego. 1600-1762, Starodawne Prawa Polskiego Pomniki, red. A. Vetulani, Seria 2: Pomniki Prawa Polskiego, Dział II: Prawo Wiejskie, t. IV, Wyd. PAN, Zakład Narodowy im. Ossolińskich. Instytut Historii Polskiej Akademii Nauk, Wroclaw, Kraków, Warszawa, $8^{\circ}$ ss. 440 , ilustr., tab., mapa (przedm. A. Vetulani, s. 1-11).

23. Sqdownictwo królewskie w sprawach chlopskich do polowy XVI wieku, Czasopismo Prawno-Historyczne, t. XVII, z. 2, s. 11-69. 
1966

24. Bibliografia prac Stanislawa Romana, Czasopismo Prawno-Historyczne, t. XVIII, z. 1, s. 314-318.

1967

25. Stanislaw Roman (1918-1965), Kwartalnik Historyczny, LXXIV, nr 2, s. $556-557$.

\section{8}

26. Ksiegi sadowe wiejskie $i$ ich znaczenie dla badań nad prawem chlopskim $w$ Polsce feudalnej, Zeszyty Naukowe Uniwersytetu Jagiellońskiego, Prace Prawnicze, t. XVII, s. 113-117.

27. Rec. [V. ProcházKA, Česká poddanská nemovitost v pozemkových knihách 16. a 17. stoleti, Praha 1963, ss. 585], Czasopismo Prawno-Historyczne, t. XX, z. 1, s. 235-241.

1971

28. Rec. [A. GAsiorowski, Urzędnicy zarzqdu lokalnego w późnośredniowiecznej Wielkopolsce, Poznańskie Towarzystwo Przyjaciół Nauk, Poznań 1970, ss. 361], Kwartalnik Historyczny, LXXVIII, nr 4, s. $940-943$.

29. O spolecznym skladzie sejmików ziemskich, [w:] Ksiega Pamiqtkowa ku czci Konstantego Grzybowskiego, red. J. Lewandowska, Wyd. Literackie, Kraków, s. 107-122.

30. Ksiega sqdowa wsi Wary. 1449-1623, Starodawne Prawa Polskiego Pomniki, red. A. Vetulani, Seria 2: Pomniki Prawa Polskiego, Dział II: Prawo Wiejskie, t. VIII, Zakład Narodowy im. Ossolińskich. Wydawnictwo PAN, Instytut Historii Polskiej Akademii Nauk, Wroclaw, Warszawa, Kraków, Gdańsk, ss. 129 (przedmowa A. Vetulani, s. 7-10).

a Rec.: J. R eczek, Język Polski (Organ Towarzystwa Miłośników Języka Polskiego), wrzesień-październik 1972, t. LII, nr 4, s. 302-305.

\section{2}

31. L'administration locale en Pologne au seuil de la II République, Entwicklungsfragen der Verwaltung in Mitteleuroppa, Studia iuridica auctoritate Universitatis Pécs publicata, Pécs, s. 139-148.

\section{3}

32. Rec. [S. KuR A Ś, Przywileje prawa niemieckiego miast $i$ wsi malopolskich $X I V-X V$ wieku, Ossolineum, Wroclaw 1971, ss. 210], Kwartalnik Historyczny, LXXX, nr 1, s. 126-129. 


\section{4}

33. Współaut.: S. Grodzis K I, Dwadzieścia pięć lat „Czasopisma Prawno-Historycznego", Kwartalnik Historyczny, LXXXI, nr 1, s. 126-132.

\section{5}

34. O tak zwanym sqdzie sześciu miast, Czasopismo Prawno-Historyczne, t. XXVII, z. 2, s. 111-119.

1976

35. Statuty Kazimierza Wielkiego w malopolskiej praktyce sqdowej $X V$ wieku, Studia Historyczne, t. XIX, z. 1 (72), s. 25-39.

\section{8}

36. O źródlach rękopiśmiennych do dziejów wsi w Polsce feudalnej, Czasopismo Prawno-Historyczne, t. XXX, z. 1, s. 197-206.

37. A. Vetulani 1901-1976, Archivum Iuridicum Cracoviense 1977*, t. X, s. 3-14.

38. Rec.: [A. Vetulani, $Z$ badań nad kulturq prawniczq $w$ Polsce Piastowskiej, Ossolineum Wrocław 1976, ss. 237], Kwartalnik Historyczny 1978*, LXXXV, nr 4, s. 1056-1058.

\section{9}

39. Rec. współaut.: B. LESIŃsKI, Nowe badania nad kodyfikacjq prawa polskiego w XVI wieku. Dwuglos o pracy Waclawa Uruszczaka [W. U R Uszcza K, Próba kodyfikacji prawa polskiego $w$ pierwszej polowie XVI wieku. Korektura praw z 1532 r., PWN, Warszawa 1979, ss. 288], Czasopismo Prawno-Historyczne, t. XXXI, z. 2, s. 203-212.

40. Współaut.: M. K AR Ás, Ksiega sqdowa państwa żywieckiego. 1681-1773, Zeszyty Naukowe Uniwersytetu Jagiellońskiego, nr 490, Prace Językoznawcze, z. 57, ss. 224.

41. Le démembrement ou l'unité d'administration en Pologne aux temps de la II République 1918-1939, [w:] Entwicklung der städtischen und regionalen Verwaltung in den letzten 100 Jahren in Mittel und Osteuropa, Internationale Rechtshistorische Konferenz, Budapest, 12-15 September 1977, Bd. 2, Budapest, s. 161-181.

1980

42. Über den sogenannten Gerichtshof des sechs Städte in Krakau, [w:] Studien zur Geschichte des sächsisch-magdeburgischen Rechts in Deutschland und Polen, Frankfurt am Main., P. Lang, Rechtshist, Reihe, Bd. 10, D. Willoweit, W. Schich, s. 122-129.

- Rec.: W. M Aisel, Czasopismo Prawno-Historyczne 1981, t. XXXIII, z. 1, s. 224. 


\section{1}

43. Sąd wyższy prawa niemieckiego w Bieczu, Czasopismo Prawno-Historyczne, t. XXXIII, z. 1, s. 1-21.

44. Die Rechtslage des Schulteisser und des Schultheissbesitzes in Polen bis zum Ende des XVI. Jahrhunderts - Ausgewählte Probleme (s. 9-15), [w:] Vorträge zur Geschichte des Privatrechts in Europa, Symposion in Krakau 9-12 October 1979, Ius Commune, Sonderhefte Bd. 15, Veröffentlichungen des Max-Planck-Instituts für Europäische Rechtsgeschich, V. Klosterman, Frankfurt am Main, ss. 231.

1982

45. Rec. [K. K A M I N K A, Sqdownictwo miasta Torunia do polowy XVII wieku na tle ustroju sqdów niektórych miast Niemiec $i$ Polski, Towarzystwo Naukowe w Toruniu, Studia Iuridica [Warszawa-Poznań-Toruń] 1980, t. XVI, z. 2, ss. 188], Czasopismo Prawno-Historyczne, t. XXXIV, z. 2, s. $236-239$.

46. Statuty Kazimierza Wielkiego, cz. II: Statuty Wielkopolskie, Poznańskie Towarzystwo Przyjaciól Nauk, Studia nad Historią Prawa Polskiego, PWN, Warszawa, Poznań, $8^{\circ}$, t. XXII, cz. 1, ss. XVI +131, nlb. 1.

- Rec.: B. Lesi nski, Czasopismo Prawno-Historyczne 1984, t. XXXVI, z. 1, s. 236-238.

47. Prawo i zwyczaj w praktyce malopolskich sqdów wiejskich $X V-X V I I I$ wieku, Czasopismo Prawno-Historyczne, t. XXXIV, z. 2, s. 1-15.

48. Rec. wspólaut. K. ORZECHOWsK I, Pierwsza próba syntezy historii administracji [Dwugłos w związku z pracą H. I zDEBSKIEGO, Historia administracji, Warszawa 1980, ss. 144]; Czasopismo Prawno-Historyczne, t. XXXIV, z. 1, s. 160-165.

\section{3}

49. Z problematyki podzialów terytorialnych państwa u progu II Rzeczypospolitej, Annales UMCS 1982*, Sec. F, t. XXXVII, z. 11, s. 211-227.

50. Głos w dyskusji na sesji: Materialy konferencji naukowej pt. „Dzieje polskiego parlamentaryzmu w okresie przedrozbiorowym", Poznań, Kórnik 11-12 maja 1982, Komitet Organizacyjny Muzeum Sejmu Polskiego, Warszawa, s. 146-149.

51. Les communautés familiales en Pologne á la lumiére des registres judiciaires ruraux du $X V^{e}$ au XVIII e siécle, [w:] Religion, Société et Politique. Mélanges en hommage à Jacques Ellul, Paris, s. 309-320.

52. $O$ wydawaniu źródel historycznych - Ankieta, Kwartalnik Historyczny, $\mathrm{XC}$, nr 1, s. 141-145.

1984

53. Sqd wyższy prawa niemieckiego w grodzie sqdeckim, Czasopismo Prawno-Historyczne, t. XXXVI, z. 1, s. 29-46. 
54. Iudicium supremum iuris Theutonici castri Cracoviensis [Streszczenie referatu przedstawionego na sesji Société d'Histoire du Droit: II Journées Internationales d'Histoire du Droit d'Amsterdam 22-25 mai 1984], Revue Historique de droit Français et Étranger, A. 62, s. 697-700.

\section{5}

55. Höhere Gerichte des Deutschen Rechts in Polen im XIV-XVI Jahren, [w:] Rechtsbehelfe, Beweis und Stellung des Richters im Spätmittelalter, wyd. W. Sellert, Böhlau, Verlag, Köln, Wien, s. 21-33.

\section{6}

56. Rec.: Malopolscy starostowie grodzcy w XV i XVI wieku [Uwagi w związku z rozprawą B. W ALDo, Urzqd starosty sqdowego w Malopolsce wXV i XVI wieku, Acta Universitatis Lodziensis, Lódź 1985, ss. 237], Czasopismo Prawno-Historyczne, t. XXXVIII, z. 2, s. $139-152$.

\section{7}

57. Nowe polskie prawo archiwalne, Archeion, t. LXXXII, s. 7-27.

58. Elekcja Augusta III $w$ świetle nieznanych rozpraw niemieckich z 1734 r., s. 59-66, [w:] Historia $i$ wspólczesność. Profesorowi Marianowi Wojciechowskiemu w sześćdziesiąta rocznice urodzin przyjaciele, koledzy, uczniowie, wyd. E. Frącki, B. Woszczyński, Naczelna Dyrekcja Archiwów Państwowych, Warszawa, ss. 384.

59. La legge archivistica Polacca del 1983, Rassegna degli Archivi di Stato [Roma], t. XLVII, nr 2-3, s. 361-397.

1988

60. Ostatnie lata sqdu wyższego prawa niemieckiego na zamku krakowskim, Czasopismo Prawno-Historyczne, t. XL, z. 2, s. 231-247.

61. Jeszcze raz o malopolskich starostach grodzkich $w X V$ i XVI wieku [w odpowiedzi Barbarze Waldo], Czasopismo Prawno-Historyczne, t. XL, z. 1 , s. $153-158$.

1989

62. Miedzynarodowe Kolokwium Towarzystwa do Badań nad Sqdem Kameralnym Rzeszy, Wetzlar 1987, Czasopismo Prawno-Historyczne, t. XLI, z. 1, s. 231-232.

1990

63. Ius supremum Maydeburgense castri Cracoviensis 1356-1794: Organisation, Tätigkeit und Stellung des Krakauer Oberhofs in der Rechtssprechung 
Altpolens, [w:] Ius Commune, Veröffentlichungen des Max-Planck-Instituts für Europäische Rechtsgeschichte. Sonderhefte Bd. 49: Studien zur Europäischen Rechtsgeschichte, V. Klosterman, Frankfurt am Main, ss. VIII +185 , tabl.

- Rec.: F. E ве L, Zeitschrift der Savigny-Stiftrung für Rechtsgeschichte 1993, T. CX, Germ. Abteilung, s. 604-606.

- Rec.: J. Matuszewski, Czasopismo Prawno-Historyczne 1992, t. XLIV, z. 1-2, s. $169-172$.

- Rec.: J. W yrozumski, Czasopismo Prawno-Historyczne 1992, t. XLIV, z. 1-2, s. $172-177$.

- Rec.: H. L Uck, Zeitschrift für Neuere Rechtsgeschichte 1992, T. XIV, H. 1-2, s. $89-92$.

- Rec.: J. Wertzel, Tijdschrift von Rechtsgeschiedenis 1992, T. LX, s. 206-208.

- Rec.: K. L uig, Zeitschrift für Historische Forschugb 1993, T. XX, H. 3, s. 387-388.

- Rec.: W. Uruszczak, Revue historique de droit français et étranger 1991, t. LXIX, s. $381-382$.

1991

64. Universitari Polacchi in Italia e Italiani in Polonia: l'accademia di Cracovia [Uczeni polscy we Wloszech. Wszechnica Krakowska i uczeni włoscy], [w:] Natio Polona. Le Universitá in Italia $e$ in Polonia, secc. XIII-XX, Mostra documentaria [Uniwersytety w Polsce i we Wloszech XIII-XX wieku, Wystawa archiwalna], - Wyd. w Polsce: Naczelna Dyrekcja Archiwów Państwowych, Kraków, Wrocław, Warszawa, Toruń, s. 39-53, il.; - wyd. we Włoszech: Ministero Beni Culturali e Ambientali; Ufficio Centrale Beni Archivistici, Roma, Perugia, Padova, Bologna 1991 , s. 39-53.

1992

65. Współaut.: D. MALEC, J. M ALEC, Gedruckte Quellen der Rechtsprechung in Europa 1800-1945, Polen, Ph. Ranieri, Frankfurt am Main, s. 765-786.

1993

66. Sqd wyższy prawa niemieckiego na zamku krakowskim a inne sqdy wyższe $z$ terenu Malopolski, Śląski Kwartalnik Historyczny, XLVIII, z. 2-3: Studia historyczno-prawne. Prace ofiarowane Kazimierzowi Orzechowskiemu w 70 rocznice urodzin, s. 113-122.

1994

67. Die Oberste Gerichtsbarkeit in Polen bis zum Ende des XVIII Jahrhunderts, [w:] Frieden durch Rechtsgeschichte das Reichskammergericht von 1495 bis 1806, Scheurmann, Mainz, $1^{\circ}$, s. 445-450. 
68. Najstarsza ksiega dekretów sądu wyższego prawa niemieckiego na zamku krakowskim, [w:] Historia prawa - historia kultury. Liber memorialis Vitoldo Maisel dedicatus, Poznań, s. 157-166.

\section{5}

69. Współpraca: K. Nehlsen-von STRYK, Decreta iuris supremi Magdeburgensis castri Cracoviensis. Die Rechtssprüche des Oberhofs des deutschen Recht auf der Burg zu Krakau 1456-1481, [w:] Ius Commune, Veröffentlichungen des Max-Planck-Instituts für Europäische Rechtsgeschichte, Sonderhefte, Bd. 68: Studien zur Europäischen Rechtsgeschichte, V. Klostermann, Frankfurt am Main, ss. XXIX +598.

- Rec.: J. Matuszewski, Czasopismo Prawno-Historyczne 1995, t. XLVII, z. 1-2, s. $215-238$.

- Rec.: F. E веL, Zeitschrift der Savigny-Stiftung für Rechtsgeschichte 1997, T. CXIV, Germ. Abteilung, s. 539-540.

- Rec.: S. SAlmonowicz, Revue historique de droit français et étranger 1995, t. LXXIII, s. 388-389.

- Rec.: W. B uk owskI, Inter finitimos 1997, t. XI, s. 36-40.

- Rec.: M. Lindner, Deutsches Archiv für Erforschung des Mittelalters 1995, T. LII, H. 1, s. 215-238.

- Rec.: W. I rgang, Zeitschrift für Ostmitteleuropa-Forschung 1998, T. XIVII, H. 1, s. $464-465$.

1996

70. Die Oberste Gerichtsbarkeit in Polen bis zum Ende des XVIII Jahrhunderts, [w:] Oberste Gerichtsbarkeit und zentrale Gewalt in Europa der frühen Neuzeit, B. Diestelkamp, Köln, s. 215-232.

1997

71. Współpraca: K. Nehlsen-von STRYK, Decreta iuris supremi Magdeburgensis Castri Cracoviensis. Die Rechtssprüche des Oberhofs de deutschen Rechts auf der Burg zu Krakau, Bd. 2: 1481-1511, [w:] Ius Commune, Veröffentlichungen des Max-Planck-Instituts für Europäische Rechtsgeschichte Frankfurt am Main, Studien zur Europäischen Rechtsgeschichte, Sonderhefte Bd. 104, V. Klostermann, Frankfurt am Main, ss. XIV $+472,1$ k. złoż.

1998

72. Sqd wyższy prawa niemieckiego na zamku krakowskim, [w:] Encyklopedia Krakowska [złożone do druku].

73. Sqd sześciu miast, [w:] Encyklopedia Krakowska [złożone do druku]. 


\section{9}

74. Raz jeszcze o zalożeniu sq̨du wyższego prawa niemieckiego na zamku krakowskim, [w:] Studia z Dziejów Państwa i Prawa Polskiego, t. IV, Łódź, s. 99-107.

Opracowal ZdZISŁAw ZARZYCKI 